\title{
Effects of Uric Acid on the Alterations of White Matter Connectivity in Patients with Major Depression
}

\author{
Hoyoung Sohn ${ }^{1 *}$, Min-Soo Kwon ${ }^{2 \star}$, Sun-Woo Lee ${ }^{1}$, Jongsoo Oh', \\ Min-Kyoung Kim¹, Sang-Hyuk Lee ${ }^{1}$, Kang Soo Lee ${ }^{1 凶}$, and Borah Kim ${ }^{1 凶}$ \\ 'Department of Psychiatry, CHA Bundang Medical Center, CHA University, Seongnam, Republic of Korea \\ ${ }^{2}$ Department of Pharmacology, School of Medicine, CHA University, Seongnam, Republic of Korea
}

Psychiatry Investig 2018;15(6):593-601

https://doi.org/10.30773/pi.2017.12.17

Following publication of the above article, the authors discovered that the p-value for group difference in sex (male/female) in Table 1 was incorrect. And the authors described unclearly whether the p-value for the sex distribution was obtained by chi-square test or Fisher's exact test. The corrected table appears below.

The authors would like to apologize for any inconvenience caused.

Table 1. Characteristics of the study participants

\begin{tabular}{|c|c|c|c|c|}
\hline & Depression $(\mathrm{N}=32)$ & Healthy control $(\mathrm{N}=23)$ & $\mathrm{t}$ & $\mathrm{p}$ \\
\hline Sex, male/female $(\mathrm{N})$ & $7 / 25$ & $11 / 12$ & & $0.08^{*}$ \\
\hline Age (years) & $41.06 \pm 13.76$ & $38.91 \pm 11.65$ & 0.608 & 0.546 \\
\hline eTIV $\left(\mathrm{mm}^{3}\right)$ & $1431259.06 \pm 124009.99$ & $1513135.98 \pm 131707.27$ & -2.354 & 0.022 \\
\hline Serum uric acid levels (mg/dL) & $4.50 \pm 1.05$ & $5.00 \pm 1.07$ & -1.712 & 0.093 \\
\hline HAMD total score & $18.31 \pm 5.15$ & - & & \\
\hline BDI total score & $21.18 \pm 7.48$ & $4.81 \pm 5.04$ & 7.78 & $<0.001$ \\
\hline BAI total score & $18.96 \pm 11.20$ & $2.44 \pm 3.22$ & 7.06 & $<0.001$ \\
\hline
\end{tabular}

Data are mean \pm standard deviation, except for the sex distribution. The p values for age, eTIV, serum uric acid levels, HAMD, BDI, and BAI scores were obtained using the independent $t$ test. *Fisher's exact test. BAI: Beck Anxiety Inventory, BDI: Beck Depression Inventory, eTIV: estimated total intracranial volume, HAMD: Hamilton Depression Rating Scale

(a) This is an Open Access article distributed under the terms of the Creative Commons Attribution Non-Commercial License (https://creativecommons.org/licenses/by$\mathrm{nc} / 4.0$ ) which permits unrestricted non-commercial use, distribution, and reproduction in any medium, provided the original work is properly cited. 